\section{INAUGURAL ADDRESS}

\section{THE NECESSITY FOR PRECISION AND THE ADVANTAGE OF CO-OPERATION.}

Delivered before the Clinical Society of London.

BY THOMAS BRYANT, F.R.C.S.,

Senior Surgeon to Guy's Hospital; President of the Society.

[AFTER thanking the members for electing him President, Mr. Bryant said :]

The work that the Society has already done has been very good, but it is yet allowable to hope that that achieved in the future may be still better. Uur predecessors have laboured productively for our advantage in various ways. Let us endeavour to improve upon their work, and so add to the sum total of attained results, that the next generation may be able to say like things of us. Let us continue to walk-as they have walked -in the paths of patient observation, and be precise alout our facts; upon these facts and observations let $a$ think closely and consistently ; and then, without fear or hesitation, carry our reasoning to its legitimate conclusions. Let us, however, in our facts, beware of accepting the false for the true, and so escape falsc reasoning; and let us be sure that the words we use convey clear thoughts. Let us, moreover, in our anxiety to be discoverers guard against announcing as a novelty some thought or observation which, though new to us, may not be so fresh to others ; remembering in the pursuit of knowledge, that our own observations are so mixed up with those of others, that our thoughts are so often merely the outcome of others' thoughts, our ideas are so constantly no more than the assimilation of the thoughts and observations of other men, that to be original is almost impossible. With respect to the use of terms, for in stance, can we say that, under all circumstances, we are as careful as we should be ; and that we never deceive ourselves or others by using phrases which, from our not being clear as to their meaning, tend in reality either to confusion, or perhaps to something .worse? To illustrate my meaning, may I ask what is meant by "strumous" disease when that term is applied to a joint, bone, or other local affection? Do we all agree as to its meaning? When we apply it, do we feel that we are conveying any accurate idea of the case under discussion to our pupils or hearers? As a teacher, I unhesitatingly say that, by the term "strumous disease," applied to any local affection, whether of joint, bone, or gland, we do not convey any clear thought. Indeed, I may say that we do the reverse ; we confuse, instead of clearing, ideas. Let me ask the members of this learned Society what they understand by the terms " strumous disease of a joint," "strumous glands," etc. ? It would be interesting to have in writing the definitions of these phrases from the individual members. Would they all agree? Would they even be at all consistent? The answers to these questions would, I fear, be in the negative. With such an admission, can we therefore possibly say that this very common term is an intelligible one, or that it ought to be retained? If we mean, when we use the term, to convey the idea that the enlargement of the affected tissue is a special one caused by struma, may I ask, what is struma? and how does it cause the local disease? Or, do we mean that it is an inflammatory affection of some form, in which the inflammatory process is modified by a condition of body which may or may not be associated with the deposition of tubercle? If the latter be the correct view, as I take it to be, why should we not say so ? and why should we not call the local affection a chronic inflammation in a strumous subject, or a chronic strumous inflammation either of the bone, of the synovial membrane, or of both, the inflammatory process being modified by the constitutional tendency of the individual, in the same way as a chronic inflam. mation in a gouty or syphilitic subject may be modified? 'It need hardly be pointed out that, by this change of expression, much good would accrue, since the alteration would tend to clear both the pathological and the clinical aspects of the case, and help our pupils instead of confusing them. At the present time, we hear of strumous, scrofulous, and tubercular disease of a joint or of bone, as if inflammation had nothing to do with the changes met with, and as if any one of the terms carried with it a precise thought.

Again, may I ask-and I do so with some amount of trepidation- what aro now to understand; when discussing the treatment of wounds, by the term "antiseptic precantions?" How, with the diversitios of practice encountered, is the expression to be interpreted ?

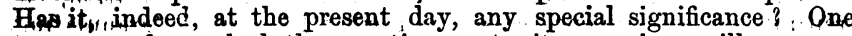
surgaon; when asked the question as to its meaning, will answer, It mpans, of course, the spray and gauze system, in one or other of its modes of application. A second, with equal decision, will apply it: to one of the many forms of antiseptic irrigation, in which the antiseptic in solution is employed either during or after an operation, and some antiseptic gauze or other dressing later on. A third surgepn will use the term as applied to some antiseptic dry or moist dressing. Hach one, at any rate, will apply it to his own system, and not to another, the former being in his own' sight orthodox, and all others heterodox. Is this confusion of meanings right, or even necessary? Is it not confusing to the seniors of the profession? and if so to them, how much more confusing it must be to our pupils. Why should we not, therefore, when we mean it, say the "aseptic". or "antiseptic spray and gauze system," or " antiseptic irrigation," or "antiseptic dry or other dressing?" Such terms would be perfectly intelligible to all, and would leave the special antiseptic drug employed as detail to be introduced in the description or not, as wished, and at the same time allow the term "antiseptic precautions" to lapse into a general expression as denoting the well established and recognised principle of antiseptic surgery. At the present day; the phrase " antiseptic precantions;": as applied to any single case, is absolutely unintelligible as indieative of any special form of practice.

Again, have we not in past times too generally mixed together cases of intestinal strangulation with those of intestinal obstruction-having been led to do so by the fact that bowel-obstruction is a common symptom of both classes of cases? And have we not, by so doing, obscured and rendered difficult of understanding cases concerning which it is very requisite that we should entertain clear views? In past prepathological ages, this confusion of terms was possibly excusable; but, with our present exact pathological and clinical knowledge, are we not obliged to admit that strangulation of the bowel is one'thing, and obstruction another? In the former class of cases, the symptoms are all due to the strangulation of the intestine, and bat little, if at all, to the obstruction; whereas, in cases of the latter class, all the symptoms are, in a general sense, due to the obstruction, and to the changes brought about by it?--these changes being experienced either at the seat of obstruction; or, when the obstruction is in the rectum or sigmoid flexure, found in the cæcum or ascending colon. Are we not therefore impelled, for the sake of a clear understanding of these two large subjects, to separate the cases, and give to each its own proper place? Shall we not, by so doing, gain clearer thoughts upon each, and thus be able, as teachers, to impart them to others?

Again, is it not most important that we should have very clear views or; such general and elementary subjects as repair and inflammation? And yet, may I ask, are our thoughts upon the relations of these two pregnant processes sufficiently clear? Do we, or do we not, in our teaching mix them up inextricably, and by so doing encourage, if not impart, erroneous views? Experience leads me, as an examiner of students, to believe that this confusion of thought is too general, and that " the healing of wounds is still supposed by some to be essentially an inflammatory process," and that even an ankylosis of a joint, the result of disorganising inflammatory changes, is "a formative termination of the inflammatory process itself." As if, indeed, repair and inflammation, from their both presenting in their respogtive courses certain histological changes which are allied, are on that aceount to be deemed identical ; and as if the union of the articular ends of the bones following a disorganisation of a joint, the result of an acuto or ehronic inflammation, can be brought about by an inflammation, or by any other process than a reparative one, which does nat begin until all inflammation has ceased, which is continued only iso long as the inflammatory process is kept in abeyance, and which ends in the desirable result of ankylosis because the reparative process is allowed to go on undisturbed, without either the aid or hindrance of inflammatory action.

In the treatment of a wound, is it not the surgeon's chief object to prevent inflammation, and is not this object, based upon the knowledge that when a wound is undergoing quick repair by primary union, and becomes the seat of inflammation, the repair at once stops, and what may have taken place in the way of repair becomes disrepair the exposed surface of the wound, if the inflammatory process cantintios, becoming the seat either of ulceration or of other destructive ohanges ?: When ulceration follows a local inflammation, it contindes so long as the inflammatory process lasts; when this stops, repair begins, what is called granulation, and this formative rerarative 
process continues and ends in cicatrisation; so long as no inflammation reappears to interfere with its progress.

When a granulating wound becomes the seat of inflammation, the reparative process at once ceases; and what had been a granulativig, soon becomes an ulcerating, surface. With these clinical facts before us, which are familiar enough to practical surgeons, there should be no difficulty in demonstrating that repair and inflammation are not only not identical, but that, whilst the one is wholly formative, the other is mostly, if not always, destructive; the one is physiological, the other pathological. Is it not, therefore, absolutely necessary that the teachers of students should have clear views upon these points, and not by such terms as " the formative termination of the inflam matory process," and other allied mixed expressions, put into students" minds a cloud of words to cover their own uncertain views? Is it not incumbent upon all teachers to enunciate that repair and inflammation are not only not identical, but that they are incompatible that repair only begins in a tissue that has been inflamed when the process called inflammation has left it ; and continues to complete its work as long as the inflammatory action is kept away ; that when inflammation attacks a wound in which repair is progressing the process is at once arrested ; and that what was repair then becomes disrepair, if not ulceration.

Allow me for a few minutes to call your attention to some practical points which require looking into ; since it seems that, in our general advance in medicine and surgery, we sometimes in special subjects recede to the practice of our ancestors. This may be said to be true in the application of ligatures to arteries in their continuity ; for some of our surgical brethren now prefer to tie in two places, and divide between the ligatures, an artery that has to be occluded for any cause thus following the practice of last century rather than that of more recent times. It is not my intention here to criticise this practice which I look upon with favour; but it would be interesting if we could obtain during the present session full particulars of the results of this revived method, and thus be able to estimate, from a practical point of view, the relative advantages of the different methods employed.

Again, may I ask, is there any truth in the accusation, which in recent times has been raised against surgeons, that the great successes which they have all round achieved in surgical operations have to a degree encouraged them not only to do, and to do rightly, what they would never have thought of doing a few years ago, but also to under take operative measures which may with some justice be looked upon as speculative, if not rash? Have our successes engendered an overestimation of our own powers, and led us to attempt and perform operations which past experience has not supported, and which seem to be less founded on scientific probabilities of success than on the sanguine hopes of their performers? Are operations upon the pylorus, or stomach, for cancer to be placed in this last category? Are there other operations which should be so classed? I have no wish to answer definitely these questions ; but I do feel that it is very necessary that the principles which have hitherto regulated operative surgery, and which have tended to suppress all experimental work, unless based on a scientific probability of success, should be carefully observed, and that we should avoid even the semblance of an experimental operation.

And here let me express for surgeons generally the satisfaction with which, in our best new surgical work, we greet the kind aid we are receiving from physicians. We are now working, more than we have ever before worked, hand in hand with them to make the diagnosis of disease of the brain, kidney, bladder, and abdomen more certain; and we are thus, with a clearer diagnosis, mutually helping to bring within the domain of scientific surgery large classes of disease which have hitherto been deemed to lie outside its pale, and have consequently been either allowed to clrift, or to pass into the surgeon's hands only when the time for effective action has passed or alnost passed, and when operative measures can at the best be carried out for purposes of relief, but not of cure.

May I now ask for even more help in this direction, and urge our medical friends to seek surgical conference early, at least in all abdominal cases in which symptoms of intestinal strangulation exist, as well as in all cases in which intestinal obstruction is present, in order that operative interference, in both classes of cases, may not be delayed longer than the scientific diagnosis of the case requires; and that the subjects of these troubles may have a chance of relief from operative measures whilst there is still a reasonable hope of obtaining it. Let us remember that exploratory operations undertaken for diagnositic purposes, but which may be used for curative ends, when the explora tory proceeding shall have cleared up or established a diagnosis (which could not have been made by other means), are as scientific as any other operations, and often more satisfactory.

Let us, therefore, encourage our medical brethren to consider closely with us surgical problems, in order that we may have their efficient help in diagnostic questions as well as their valuable support when action, by way of operation, is called for ; and let us employ the opportunity to convince them of the expediency of expediting action as soon as the necessity for action has arrived, and at the same time to demonstrate the evil (ffects of postponing operative interference when such is demanded for either diagnostic or curative ends. In surgery, as in so many conditions of life, action, to be effective, must be desisive and not dilatory; it should ever follow closely upon decision.

These remarks which I have thus brought before you, I have been tempted to make under an impression that they will be generously received, and under the conviction that they have reference to subjects of grave clinical importance. Some of the subjects to which I have alluded are important in themselves ; others are important on account of the principles embodied in them.

Should my observations appear to some too critical, let me say that they have not been made in any captious spirit, but with the feeling that it is always better for us to criticise our own work than to leave such criticism to others; that, as your president, it is as much my duty to point out what I believe to be defects in our work or in our mode of work, as it is to indicate the direction in which we should travel, and in the hope that, by so doing, I am likely to receive the full support of the members of this Society in what I believe to be the best for the "cultivation and promotion of practical medicine and surgery," objects for which this Society was formed, and which we all have so much at heart.

\section{ON OPERATIVE DILATATION OF THE ORIFICES OF} THE STOMACH :

BEING A SUMMARY OF TWO PAPERS ON THIS SUB.JECT, BY PROFESSOR LORETA, OF BOLOGNA.

By T. HOLMES, M.A., F.R.C.S., Senior Surgeon to St. George's Hospital.

Signor Loreta, Professor of Surgery in the University of Bologna, has lately published (in the Memorie dell' Accademia delle Scienze dell Istituto di Bologna, Ser. iv, vols. 4 and 5) two extremely interesting tracts : the first on Digital Dilatation of the Pylorus, and the second on Instrumental Dilatation of the Esophagus ; each of them giving the history of two cascs, in which the proposed operation had been carried out with perfect success. In the former case, the operation is intended as a substitute for the resection of the pylorus; and, in the second, for gastrostomy. Each of them is intended only for cases of a chronic and non-malignant character-simple or fibrous stricture and, in the case of the oesophagus, also cicatricial contraction after injury.

As I find that the subject is almost unknown to my surgical colleagues, and as the notices which have hitherto appeared of Signo Loreta's operations in our medical journals have been very imperfect I propose to give a summary of his pamphlets. The author's courtesy has also put me in possession of the subsequent most satisfactory experience of these operations, in the practice of other surgeons in Italy, as well as his own; and a sufficient length of time has elapsed to enable him to affirm the permanence of the cure so obtained.

I. Dilatation of the Pylorus. - The operation on the pylorus is best illustrated by the history of the first patient operated on, which is thus abbreviated from the original. $\mathrm{He}$ was a man, aged 47, named Cecconi, who had suffered from dys peptic symptoms for twenty years, and had been treated in the hospital at Bologna, four or five years before the date of operation for an ulcer of the stomach, near the pylorus (as then diagnosed). The symptoms were relieved, and for a time he returned to work, but soon relapsed; and, when admitted in August, 1882, was in the last stage of emaciation and exhaustion. The only food he could take was milk, in small quantity ; every other species of food was at once rejected. Whenever he took any food, he could feel its passage towards the right hypochondrium, whence it returned at once towards the left, causing ernctations, and frequently vomiting. The man was as lean as possible, pallid, and with a rough skin entirely devoid of any panniculus adiposus. The outline of the distended stomach could be seen through the abdominal walls, and it felt tense and elastic; the resonance extended from the fifth rib to the umbilicus. The contents of the stomach, drawn off by the pump, were yellow, containing a few coagula

1 This operation would perhaps be more exactly described as "Dilatation of the Cardia and Casophagus." 